Во-вторых, команды решения проблем - временные группы, используемые для выявления и устранения причин проблем.

В-третьих, естественные рабочие группы - небольшие группы квалифицированных рабочих, которые разделяют обязанности. В этих командах используются группы вовлечения сотрудников, самоуправляющиеся группы и кружки качества.

Таким образом, процессный подход означает создание процессов организации для работы как интегрированной и законченной системы. Процессный подход может облегчить внедрение любой системы менеджмента, и преимущества его внедрения значительны. В числе основных преимуществ- сосредоточение внимания на более важных («рискованных») процессах и их результатах; улучшенное понимание, определение и интеграция взаимозависимых процессов; систематическое управление планированием, внедрением, проверками и улучшением процессов и системы менеджмента в целом; более эффективное использование ресурсов организации; достижение целей и политики в области качества и в целом повышение удовлетворенности клиентов за счет учета их требований [4].

В заключении стоит отметить, что проанализировав практические аспекты внедрения процессного подхода применительно к организации можно утверждать, что именно процессный подход лучше всего поддерживает политику и тактику TQM и является ключевым требованием ISO 9001: 2015.

$$
* * *
$$

1. Володина, Н.Л. Система менеджмента качества как концепция управления изменениями / Н.Л. Володина // Вестник Воронежского государственного технического университета. - 2014. - Т.10. №3. -C.108-110.

2. Чайка, ИИ. Стандарт ИСО 9001:2015. Что нас ожидает? / И.И. Чайка // Вопросы стандартизации. 2014. - №2. - C.8-11.

3. Никулина, Ю. Н. Повышение конкурентоспособности организации сферы услуг с позиции системы управления качеством / Никулина Ю. Н., Вакушкина О. И. // Universum: экономика и юриспруденция,2017. - № 3 (36). - С. 17-20.

4. Демина, Н.В. Использование преимуществ стратегического менеджмента для повышения конкурентоспособности российских предприятий // Менеджмент качества. - 2020. - No2. - С.106114.

\title{
Пригульный А.Г. \\ Схемы и модели описания процессов в предпринимательской деятельности
} АНО ВО «Университет МПА ЕврАзЭС» (Россия, Санкт-Петербург)

\author{
doi: $10.18411 / \mathrm{j}-06-2021-87$
}

\section{Аннотация}

Бизнес-процессы представляют собой действия, которые предпринимательские организации осуществляют для того, чтобы произвести и доставить ценность до потребителя, а также необходимые для этого ресурсы. Количество бизнес-процессов велико и охватывает либо часть подразделений, либо все подразделения компании в целом.

Одним из способов повышения конкурентоспособности и эффективности деятельности организаций является применение руководителями инструментов описания и формализации бизнес-процессов. Если бизнес-процессы ясны и регламентированы, это упрощает деятельность сотрудников и руководителей компаний, улучшает взаимодействие с клиентами и партнерами.

Целью статьи является рассмотрение основных элементов описания бизнеспроцессов, используемых менеджерами в предпринимательской деятельности.

Ключевые слова: предпринимательская деятельность, бизнес-процессы, описание бизнес-процессов. 


\section{Abstract}

Business processes are the actions that entrepreneurial organizations take in order to produce and deliver value to the consumer, as well as the resources required for this. The number of business processes is large and covers either part of the divisions or all divisions of the company as a whole.

One of the ways to improve the competitiveness and efficiency of organizations is the use by managers of tools for describing and formalizing business processes. If business processes are clear and regulated, it simplifies the activities of employees and company leaders, improves interaction with customers and partners.

The purpose of the article is to consider the main elements of the description of business processes used by managers in business.

Keywords: entrepreneurial activity, business processes, description of business processes.

В современной бизнес-организации невозможно обойтись без описания процессов. Системно или хаотично, случайно или целевым образом, на научной основе или благодаря интуиции, предприниматели фокусируют внимание на необходимости описания процессов.

Как показывает практика совершенствование бизнес-процессов дает возможность предпринимателям добиться значительных экономических эффектов (повышения выручки, рентабельности и снижения затрат), а также улучшения рыночных конкурентных позиций организаций.

Цели описания процессов могут существенно отличаться в зависимости от того, для какой организации проводится описание бизнес-процессов.

В случае, если мы имеем дело с организацией, завоевавшей авторитет и репутацию среди конкурентов и потребителей, целями описания процессов могут быть следующие:

$\checkmark$ определение зон ответственности в команде руководителей на различных уровнях управления организацией;

$\checkmark$ установление оптимального режима взаимодействия подразделений организации в формате входа/выхода всех видов процессов;

$\checkmark$ создание системы процессов в рамках объектной и структурной моделей для эффективного управления организацией;

$\checkmark$ использование программного обеспечения для того, чтобы автоматизировать разработку разнообразных регламентов: положений о департаментах и подразделениях, должностных инструкций сотрудников, регламентов, описывающие бизнес-процессы и способы выполнения действий для их реализации и др.

В случае, если предметом нашего интереса будет стартап, то готовимся к созданию и продвижению стартап-проекта с высокой степенью неопределенности. В этом случае цели описания процессов будут иными:

$\checkmark$ определение перспективных зон ответственности среди участников команды, потенциально готовых занять руководящие должности после запуска стартапа по мере становления новой организации;

$\checkmark$ описание направлений деятельности новой организации по ключевым процессам работы с потенциальными потребителями (привлечение, удержание, воспитание лояльности); создания, движения и развития ценностного предложения (от минимально необходимого продукта к продукту с оптимальным набором функций) для регламентации работ с потребителями (клиентами, покупателями); 
$\checkmark$ использование результатов работ по описанию и регламентации процессов для достижения общего понимания проблем стартапа и становления организации среди участников команды;

$\checkmark$ создание регламентов: положений по организации ключевых бизнеспроцессов; внутренних и внешних коммуникаций; маркетинга; бюджетирования; сервиса; должностных инструкций и т.д.

По утверждению экспертов, провести описание бизнес-процесса не сложно [1]. Эта работа вполне доступна для любого сотрудника. Однако необходимо учитывать, что полученная схема будет лишь отчасти отражать реальность [2]. Рассмотрим основные аспекты, которые необходимо учитывать при выполнении работ по описанию бизнес-процессов.

Для описания бизнес- процессов используются:

- нотации - методики создания и развития схем бизнес-процессов с использованием системы определенных правил и условных обозначений;

— схемы процессов - графическое изображение процессов;

- модели процессов - комплексное описание процесса, создаваемое для решения задач управления организациями. Модели создается с помощью графических схем, таблиц и/или текстовых описаний.

Нотации бизнес-процессов.

При поверхностном суждении, выбор нотации представляется ключевой задачей для получения объективного результата описания бизнес-процесса. Однако выбор нотации не определяет всей полноты успеха работы по описанию и регламентации процессов организации. Эту задачу можно решить системно, на основе комплексного подхода, учитывающего множество различных факторов.

Схемы бизнес-процессов.

Принято выделять схемы бизнес-процессов [3] двух уровней:

1. Схема процессов верхнего уровня - схема предстоящих работ по созданию процесса может быть описана агрегировано, то есть, в виде важнейших блоков описания предстоящих действий.

2. Схема процессов детализированного уровня - схема работ по созданию процесса может быть описана детализировано, то есть в виде отдельных операций. Уровень детализации схемы процесса зависит от состава управленческих задач, которые необходимо решить.

Эксперты предлагают использовать два варианта описания схем бизнеспроцессов [1].

Первый вариант представляет собой использование алгоритмов, например, блоксхем, отражающих последовательность работ, которые составляют бизнес-процесс. К примеру, вход-логические условия-обработка-выход [4,5].

Использование алгоритмов и блок-схем чаще всего связано с необходимостью решения следующих задач:

$\checkmark$ регламентация логики исполнения деятельности;

$\checkmark$ объяснение, как реализуется процесс и какой следует ожидать результат;

$\checkmark$ доведение информации, кто делает, в какой последовательности;

$\checkmark$ объяснение, какие документы, в какой последовательности создаются.

Второй вариант связан с представлением бизнес-процессов в виде потока объектов. К примеру, входной поток - преобразование объектов-выходной поток. При использовании данного варианта потоки могут быть представлены в виде документов, информационных и материальных ресурсов и др.

Потоковые схемы применяются для решения следующих задач:

$\checkmark$ исследование деятельности организации по схеме «вход-выход»; 
$\checkmark$ организация процесса: на входе, - поступление ресурсов, на выходе получение результата в виде продукта (товары, услуги, работы);

$\checkmark$ организация процесса: на входе, - обнаружение проблемы потребителя (выявление спроса потребителя на продукт), на выходе, - решение проблемы (создание предложения потребителю).

В одной и той же ситуации начало и окончание бизнес-процесса может быть определено по-разному.

Процесс может быть представлен, как начало действия-действие-завершение действия в рамках определенных ограничений.

Если действие определяется как функция, то бизнес-процесс может быть представлен, как начало действия функции - реализация функции-окончание действия функции.

Модель бизнес-процесса представляет собой совокупность элементов, которые характеризуют существующий процесс либо создаваемый бизнес-процесс. В модель могут быть включены полностью или частично основные, вспомогательные, управляющие и иные процессы $[1,6]$.

Модели в общем виде представляют собой упрощенное представление явлений и действий. В настоящее время модели представлены в широком диапазоне, например, физические, математические, текстовые, графические и др.

Моделирование очень активно применяется в деятельности бизнес-организаций для исследования, объяснения и измерения рыночных процессов, планирования и прогнозирования спроса, предложения, других процессов и явлений.

Моделирование бизнес-процессов может осуществляться с разной степенью детализации: от абстрактного до детального.

Модель обычно представляет процесс с различных точек зрения, отражающих цели разных участников описания процессов (руководителей организации, владельцев процесса, исполнителей операций).

Модель процесса состоит из пиктограмм (условных обозначений, изображающих потоки работ, данных, событий, решения и т.д.). Модель может содержать изображение и информацию об элементах процесса; связях между элементами; связях с окружающей средой; поведении участников процесса.

Назначение моделей бизнес-процессов:

a) помогает четко понять, что и каким образом предстоит сделать и какую работу выполнить;

b) позволяет создать регламент, зафиксировать порядок выполнения предстоящей работы;

c) дает возможность задать параметры работы, сроки, необходимые ресурсы, организовать и контролировать исполнение работы;

d) представляет описание бизнес-процесса при помощи нотации, использующей специализированный язык и фиксирующей результат в виде таблиц, схем, текстов;

е) помогает понять содержание процесса, создать регламент бизнеспроцесса и схему управления бизнес-процессом.

Модели бизнес-процессов применяются в практической деятельности владельцев процессов (создателей и руководителей бизнес-процессов на различных уровнях управления организацией), администраторов, аналитиков и методологов процесса (сотрудников), для решения ряда профессиональных проблем, заключенных в следующих вопросах:

$\checkmark$ По каким направлениям следует развернуть работы по улучшению текущей деятельности организации?

$\checkmark$ Какие действия следует предпринимать, чтобы повысить производительность труда? 
$\checkmark$ Как повысить экономическую эффективность деятельности?

$\checkmark$ Какие работы необходимо выполнять для исполнения процесса и достижения ожидаемого результата?

$\checkmark$ Что считать результатом каждого вида выполняемых работ?

$\checkmark$ Если выполняется несколько видов работ, интегрированных в одну цепочку, то что можно считать выходом первой работы и входом второй?

$\checkmark$ Каким видам ресурсов можно отдать предпочтение для выполнения запланированных работ?

Таким образом, модель бизнес-процесса может быть представлена описанием работ, выполняемых в соответствии с требованиями к качеству, обеспечивающими необходимый уровень эффективности.

\section{Вывод.}

Успешная деятельность бизнес-организации во многом определяется тем, как в ней построены и организованы бизнес-процессы.

Результаты исследования показывают, что использование инструментов описания и формализация позволяет совершенствовать бизнес-процессы. Основными аспектами при описании бизнес-процессов являются нотации, схемы процессов и модели процессов.

\section{$* * *$}

1. Свод знаний по управлению бизнес-процессами: ВРМ СВОК 3.0 / Под ред. А.А. Белайчука, В.Г. Елифёрова. Москва: Альпина Паблишер, 2016.

2. Репин В.В. Бизнес-процессы. Моделирование, внедрение, управление. Москва: Манн, Иванов и Фербер, 2013.

3. Кондратьев В.В., Кузнецов М.Н. Показываем бизнес-процессы. Эксмо; М.; 2008.

4. Рыбаков М.Ю. Бизнес-процессы. Как их описать, отладить и внедрить. Москва. Издательство Михаила Рыбакова, 2019.

5. Шенталер Ф., Карле Т., Обервайс А., Фоссен Г. Бизнес-процессы. Москва: Альпина Паблишер, 2019.

6. Ротер М., Шук Д. Учитесь видеть бизнес-процессы: Построение карт потоков создания ценности. Москва: Альпина Паблишер, 2015.

\section{Сарбей С.В., Антонова Н.Л. \\ Онлайн - бизнес: реальность и перспективы}

Сургутский Государственный Университет (Россия, Сургут)

doi: $10.18411 / \mathrm{j}-06-2021-88$

\section{Аннотация}

В данной статье актуализируется вопрос о ведение онлайн-бизнеса в 21 веке. Была рассмотрена история появления данной сферы занятости, проведен анализ как сильных, так и слабых сторон онлайн-заработка, сделаны выводы, основанные на приведенной статистике.

Ключевые слова: бизнес, целевая аудитория, интернет-площадка, фриланс.

\section{Abstract}

This article updates the question of doing online business in the 21 st century. The history of the emergence of this sphere of employment was considered, an analysis of both the strengths and weaknesses of online earnings was carried out, conclusions were made based on the statistics provided.

Keywords: business, target audience, online platform, freelance. 